\title{
Some gender differences in performance in senior high mathematics examinations in mixed high schools
}

\author{
Leonard Kyei ${ }^{1}$, Benjamin Apam ${ }^{2}$, K. Sagary Nokoe ${ }^{1}$ \\ ${ }^{1}$ University for Development Studies, Department of Statistics, Navrongo \\ ${ }^{2}$ Bolgatanga Polytechnic, Department of Statistics, Bolgatanga
}

\begin{abstract}
The paper examined the expected causes of gender difference in the performance of mathematics among boys and girls in mixed senior high schools in the Upper East Region of Ghana. Questionnaire and interviews were used for data collection. Results indicated that, boys' performances outweighed those of girls, as it was evident that girls' lack of self-confidence was a contributing factor or a major cause of the difference in performances. It was also found out that, students' interest in mathematics was influenced by personal interests and teaching methods. On students' performance analysis, the class of the student, the number of educated people in the student's house and the sex of the student were found to be linearly related. Furthermore, perceived gender difference caused school drop-out and poor choices of girls relative to boys. It was inferred that, this aspect of the study, for gender equity in decision making cannot be achieved once gender difference in mathematics ability of boys and girls is not resolved. Also, the capacity to educate pupils from the elementary schools will remain incomplete as women always passed on these perception and belief to younger generation even before they start to make their own choice in academics.
\end{abstract}

Keywords: performance, mathematics, Logistic regression, teaching methods, personal interest

\section{INTRODUCTION}

Gender in common usage refers to the sexual distribution between male and female. Social scientists however refer to the term a social construction rather than a biological phenomenon. The choice of subject of study, Mathematics, is guided by the literature. Rene Descartes (15961650), a philosopher, argued "that mathematics or the "mathematicised" sciences ensured our understanding of the world" (Nokoe, 2008). Science, to Descartes, relies on the power of mathematics. Nokoe (2008) rejected the tempting arguments of George Berkeley (1685-1753) and David Hume (1711-1776) that mathematics is rooted in bundles of assumptions about infinite desirability in want of any basis in experience. In reaction, Nokoe (2008) had argued that, mathematics carries an optimal degree of consistency, certainty and credibility to guide the Sciences.

The great misconception about mathematics is the notion that mathematics is about formulas and computations that need to be memorized. This view has trifled and thwarted the efforts of students more than anything else. This misconception has moved further to identify mathematics as a male subject in the basic and second cycle schools in the Ghanaian society. Our nation has made great strides towards achieving gender mainstreaming in education over the past years. Now, more than ever before, the door is wide open for women to seek and obtain careers that their mothers have never thought possible.

It is clear that major academic hurdles have been successfully cleared by and for women. However, evidence suggests mathematics- and science-related careers continue to be dominated by men. Moreover, evidence is beginning to mount in support of the fact that the difference in mathematical success between men and women lies not within abilities, but within attitudes and expectations of success. Obviously, this maladaptive societal attitude renders numerous problems, but perhaps most detrimental of all is the fact that girls are not realizing their full potential, thus limiting them not only in the classroom, but also in future career choices.

Tobias (1978) was among early researchers to identify and research a disabling condition known as math anxiety. This can be described as a set of beliefs and behaviours that prevent students from performing in mathematics. Although some males have math anxiety, it is primarily seen in females. Individuals with math anxiety may be intellectually capable of doing mathematics, but their emotional 
response literally locks up their ability to perform. Classic symptoms include quickened pulse, sweaty palms, and an inability to think. It is thought that females become math anxious because of erroneous but prevalent beliefs like (1) math and science are male domains; (2) math and science must be done quickly; or (3) there is only one-way to solve a math problem.

Many years ago, people believed it was not "healthy" for women to receive an education. Specifically, "doctors warned that education redirected blood, initially destined for the ovaries to the brain. The result: educated women would be less likely to reproduce and more likely to go insane" (Sadler, 1999 , p. 24). Although seemingly ridiculous statement today, that particular belief kept many women far from education years ago. Until around the middle of the twentieth century, gender differences in intellectual abilities were considered "natural" or inherently dependent on biological sex differences (Sadker and Sadker, Klein 1991).

It seems appropriate to discuss sex-related differences in mathematics in connection with algebra. Girls and boys often begin to study algebra concepts in senior high school. Myra and Sadker (1991) found that females lose self-esteem when they enter middle school. According to Fennema's (1974) classic research, differences between females' and males' learning of mathematics increased as they moved into adolescence. Thus, females have problems with self-esteem and learning mathematics just when they are beginning to study algebra, the foundation of most high school and college mathematics courses.

Further studies by Fennema and Sherman (1977, 1978) documented differences for females and males in both achievement and participation in mathematics courses in grades 6 through 12. As example of the attitudes studied, males were found to be more confident in their ability to learn mathematics than females and males perceived mathematics to be more useful to them than females. While exploring the gender differences in mathematics performance, Campbell and Storo (1996) found out that, certain myths have become widely accepted as truth. One such myth is that "women are qualitative, men are quantitative" (p.5). Another myth is the linkage of a math-gene in male. Parents and teachers alike hold lower expectations for girls in math and science than they do for boys. In addition to these myths, most models of orientation to mathematics emphasize on social factors such as gender stereotypes. It is these gender stereotypical attitudes over the years, held by teachers and absorbed by students that play a major role in the future mathematical performance of females (Banaji, Greenwald and Nosek, 2002).

Before we attempt to identify and solve this problem, we must first scrutinize and explore its many roots. The first major issue that needs to be explored is teachers' beliefs about gender differences, specifically in mathematics ability. Teachers, sometimes attribute students' success and failure in mathematics to ability or effort, depending on the gender of the student. A second one that needs to be examined is the difference in the amount of attention and types of attention teachers give to female students as compared to that of the male student in the classroom. Streitmatter (1997) found that "females receive less attention, both positive and negative from teachers than do males" (p. 16). Additionally, Sadler and Sadler (1991) found that teachers' questioning methods and praise differed substantially for girls and boys. Specifically, "females tend to be praised simply for trying, whereas teachers tend to withhold praise for males until they produce a correct answer" (Streitmatter, 1997, p.16). Both of these foster an atmosphere favourable to male learning while overlooking the needs of female students.

The third one, which needs additional study, is that in the classroom, girls are less likely to engage in risktaking activities such as asking questions and providing answers than are boys. In support of this, Sadler and Sadler (cited in Streitmatter, 1997, p.18) found that "many girls are reluctant to risks in coeducational classrooms in part due to boys' domination". As Streitmatter (1997) pointed out, "students who are active participants in their own education tend to be higher achievers" (p. 18). Thus, without engaging in risk-taking activities in the classroom, it is not possible for girls to achieve their full academic potential in mathematics.

This leads us to the forth examination; girls lack of self-confidence in their ability to perform in mathematics. Charles Shield stated in his 1991 article, Girls, math and the glass ceiling that: confidence is one part of self-concept and has to do with how sure a student is of his/her ability to learn new mathematics and do well on mathematical tasks. Confidence influences as student's willingness to approach new material and to persist when the material become difficult. Despite the immediate difficulty of the task, the student persists when she is 
confident that a solution will be found or that the material will be understood.

To this in mind we set out to investigate these objectives thus; to determine the main causes of gender differences on academic performance or success in mathematics in the Bawku West and Kassena Nankana Districts, to find out the reasons why students like/dislike mathematics, to find out the effect(s) and impact in the districts and to make recommendation(s) and suggestion(s) to the Ghana Education Service (GES) and teachers on how to reduce gender difference on academic success in mathematics in the districts if not wipe out completely.

\section{METERIALS AND METHODS}

Research Design and Sampling Techniques: This study is centred on the Bawku West and Kassena Data were obtained using the stratified multistage sampling. There are two major study sites - Bawku West and Kasena -Nankana districts. Districts are the strata. In each stratum, first stage units are the schools, while the classes constitute the second stage units. Two schools were selected as first stage units in each of the districts.

Samlpe Size and Data Collection: The main tool used is a questionnaire. A sample size of $n=250$ of students was considered where the sample size for each school was chosen using proportional allocation. 15 teachers in all schools were captured in the study.

The sample size for each school was calculated as follows:

$P_{k}=\frac{N_{k}}{N} \times n$

Where $P_{k}$ is the sample size for the $k^{\text {th }}$ first stage unit (school), $N_{k}$ is the population size of the $k^{\text {th }}$ first stage unit; $\mathrm{N}$ is the total population of all the selected first stage.

The schools included in the sample are; Zebilla Senior High School (ZSHS), Kusanaba Senior High School(KSHS), Navrongo Senior High School (NSHS) and Notre Dame Senior High School (NDSHS) all in the Upper East Region. The respective populations of the schools are 614, 440, 1223 and 248. Therefore, the total population of all the sampled schools is 2536 .

Using the relation above, a proportional allocation of sample sizes to all the sampled schools are calculated below. These gave 61 and 43 sampling units for Zebilla and Kusanaba SHS (in Bawku District) respectively, and 121 and 25 respectively for Navrongo and Notre dame in KN District. Two types of data were collected from each of the schools for the study. Primary data was through questionnaire applied to samples, and secondary data through the internet, textbooks, journals, and study text from the library.

Statistical Models Used: The statistical models used are logistic and multiple linear regression models. The logistic model was used since the data is basically qualitative. The logistic model is of the form;

$E(Y)=\frac{e^{\beta_{0}+\beta_{1} x_{1}+\beta_{2} x_{2}+\cdots+\beta_{k} x_{k}}}{1+e^{\beta_{0}+\beta_{1} x_{1}+\beta_{2} x_{2}+\cdots+\beta_{k} x_{k}}}$

where $\beta_{0}$ is the intercept, $x_{1}, x_{2}, \ldots, x_{n}$ are explanatory variables while $\beta_{1}, \beta_{2}, \ldots, \beta_{n}$ are significant $(p<0.05)$ estimates of the responds variables.

The multiple regression model was used to find the relationship between the performance (last examination score) of students, age of the sampled students, number of educated person in the house and gender of the respondent. The model is given as;

$Y=\beta_{0}+\beta_{1} x_{1}+\beta_{2} x_{2}+\beta_{3} x_{3}$

where $Y$ is the last exam score; $x_{1}$ is the age of respondent; $x_{2}$ number of educated persons in the respondent's house and $x_{3}$ is the sex of the respondent.

\section{DATA ANALYSIS}

Logistic Regression: The logistic regression was used to analyse two response items - GEN_DIF [which means that "do you agree that boys perform better than girls in mathematics?" with binary responses yes (0) and no (1)] and LIKE_M [Like mathematics, yes(0) and no (1)] that are of serious concern.The model fitted GEN_DIF, against the explanatory variables using the question "[W_CAUSE] what is the reason to liking mathematics?" in the student questionnaire. Responses from both students and teachers are used in this analysis. nterpretation of the results uses more of the codes than the question or options/sub options.

The predictors are coded as shown below:

W_CAUSE1 - girls lacks self-confidence 
W_CAUSE2 - teacher's questioning methods

W_CAUSE3 - teachers praise boys and girls differently

W_CAUSE4 - teacher's belief of gender difference

The overall model analyzed is statistically significant (Likelihood Ratio $x^{2}=39.3581, p=0.0001$ ) and the percent concordant $(71.7 \%)$ is large enough to say that the predictor variables (W_CAUSE1 W_CAUSE4) explains much of the variations in GENNDIF.

Table 1: Analysis of the Maximum Likelihood Estimates for GEN_DIF and W_CAUSE

\begin{tabular}{|l|l|l|l|l|l|}
\hline Parameter & DF & Estimate & Standard Error & Wald Chi-Square & Pr $>$ ChiSq \\
\hline Intercept & 1 & 1.0656 & 0.1668 & 40.8280 & $<.0001$ \\
\hline w_cause1 0 & 1 & -0.9333 & 0.1660 & 31.6267 & $<.0001$ \\
\hline w_cause2 0 & 1 & 0.3495 & 0.1667 & 4.3945 & 0.0361 \\
\hline w_cause3 0 & 1 & -0.1389 & 0.1674 & 0.6889 & 0.4065 \\
\hline w_cause4 0 & 1 & 0.0163 & 0.1648 & 0.0097 & 0.9215 \\
\hline
\end{tabular}

Further the second model fitted using LIKE_M which means "do you like mathematics?" (Table 2). The responses in the following question, "[W_L_M] what is your reason?" are the predictors also for this response variable are

[W_L_M1] Teaching methods

[W_L_M2] personal interest

[W_L_M3] hates it

[W_L_M4] people say it is difficult

A logit regression was also used to predict whether the student like mathematics and why using teaching methods (W_L_M1), personal interest (W_L_M2), hates it (W_L_M3) and people say it is difficult (W_L_M4). All observations were used in the analysis. The overall model analyzed is statistically significant which indicates that the overall model is statistically significant $\left(x^{2}=40.1859, p\right.$-value $=$ 0.0001). The percent concordant below table D indicates that $68.80 \%$ of the variance in LIKE_M $=1$ can be predicted from the variables W_L_M1, W_L_M2, W_L_M3, and W_L_M4.

\section{RESULTS}

From table 1, it can be seen that W_CAUSE1 and W_CAUSE2 were significant at $5 \%$ significant level because their respective P-values are less than 0.05 .

However, the model of best fit from the stepwise selection model is given by:

$E(Y)=\frac{e^{1.066-0.933 w_{-} \text {cause } 1+0.350 w_{-} \text {cause } 2}}{1+e^{1.066-0.933 w_{-} \text {cause } 1+0.350 w_{\text {_cause } 2}}}$
Table 2: Odd Ratio Estimate for GEN_DIF \&W_CAUSE

\begin{tabular}{|ll|l|l|l|}
\hline \multicolumn{1}{|l|}{ Effect } & & $\begin{array}{l}\text { Point } \\
\text { Estimate }\end{array}$ & \multicolumn{2}{l|}{$95 \%$ Wald Confidence Limits } \\
\hline $\begin{array}{l}\text { W_cause1 } \\
\text { vs 1 }\end{array}$ & 0 & 0.155 & 0.081 & 0.296 \\
\hline $\begin{array}{l}\text { W_cause2 } \\
\text { vs 1 }\end{array}$ & 0 & 2.012 & 1.047 & 3.868 \\
\hline $\begin{array}{l}\text { W_cause3 } \\
\text { vs 1 }\end{array}$ & 0 & 0.757 & 0.393 & 1.460 \\
\hline $\begin{array}{l}\text { W_cause4 } \\
\text { vs 1 }\end{array}$ & 0 & 1.033 & 0.541 & 1.971 \\
\hline
\end{tabular}

Table 3 shows the coefficients, their standard errors, wald chi-squared and associated p-values. Both W_L_M1 $(X 2=27.443, p$-value $=0.0001)$ and W_L_M2 ( $\mathrm{X} 2=12.4509, p$-value $=0.0004)$ are statistically significant whereas the coefficients of W_L_M3 $\left(x^{2}=1.6401, p\right.$-value $\left.=0.2003\right)$ and W_L_M4b $\left(X^{2}=0.5329, \quad p_{r}=0.4654\right)$ are not significantly different from 0 .

The model of best fit from the stepwise selection model is given by: 
$E(Y)=\frac{e^{0.9568-0.9027 w_{-} l_{-} m 1-0.6163 w_{-} l_{-} m 2}}{1+e^{0.9568-0.9027 w_{-} l_{-} m 1-0.6163 w_{-} l_{-} m 2}}$

Table 3: Analysis of the Maximum Likelihood Estimates for LIKE_M and W_L_M

\begin{tabular}{|l|l|l|l|l|l|}
\hline Parameter & DF & Estimate & Standard Error & Wald Chi-Square & Pr $>$ ChiSq \\
\hline Intercept & 1 & 0.9568 & 0.1838 & 27.1125 & $<.0001$ \\
\hline W_1_m1 0 & 1 & -0.9027 & 0.1723 & 27.4453 & $<.0001$ \\
\hline W_1_m2 0 & 1 & -0.6163 & 0.1747 & 12.4509 & 0.0004 \\
\hline W_1_m3 0 & 1 & 0.2498 & 0.1951 & 1.6401 & 0.2003 \\
\hline W_1_m4 0 & 1 & 0.1298 & 0.1778 & 0.5329 & 0.4654 \\
\hline
\end{tabular}

From table 4 it can be seen that the odds of admitting that the student dislike mathematics (versus the student likes mathematics) decreases by a factor of 0.164 for the predictor $\mathbf{W} \_\mathbf{L} \_\mathbf{M} 1$, and for $\mathbf{W} \_\mathbf{L} \_\mathbf{M} 2$, such odds decreased by a factor of 0.292 . However, for W_L_M3 and W_L_M4, the odds of admitting that the student does not like mathematics (vs. like mathematics) increases by a factor of 1.648 and 1.296 respectively.

The multiple regression statistical method was used to find out if there is any relationship between the variables listed below and student performance in mathematics examination considering the last exam score of the student as the response or dependent variable:

[EX_S] The last exam score of the student

[CLASS] the class/form of the student

[AGE] the age of the student

[SEX] the sex of the student $($ male $=1$ female $=0$ )

[NUM_PLE] number of people in the student's household

[NUM_EDU] number of educated people in the student's household

The significance level considered for variable entry and variable removal were 0.05 and 0.10 respectively. The results indicates that, the model as a whole is statistically significant $(F=10.95 p=0.0001)$. Comparing the $p$-value of 0.0001 to $5 \%$ significance level, it is evident that the group of variables age, class, number of people in the respondent's household, number of educated people in the household and the sex of the student can be reliably used to predict the outcome of examination score (EX_S) of the student. This tests the variables as a group but cannot be used to predict which variable contributes to students examination score in mathematics.

The proportion of variance in the examination score in mathematics which can be predicted from the group of variables age, sex, class, number of people and number of educated people in the household is given by $18.33 \%$ whereas the unit-less measure of variation in the data is 33.294 . To determine the model of best fit, the stepwise selection method was used.

Table 4: Odd Ratio Estimates for LIKE_M and W_L_M

\begin{tabular}{|ll|l|l|l|}
\hline Effect & & $\begin{array}{l}\text { Point } \\
\text { Estimate }\end{array}$ & $\begin{array}{l}\text { 95\% Wald Confidence } \\
\text { Limits }\end{array}$ \\
\hline $\begin{array}{l}\text { W_1_m1 } \\
\text { vs 1 }\end{array}$ & 0 & 0.164 & 0.084 & 0.323 \\
\hline $\begin{array}{l}\text { W_1_m2 } \\
\text { vs 1 }\end{array}$ & 0 & 0.292 & 0.147 & 0.578 \\
\hline $\begin{array}{l}\text { W_1_m3 } \\
1\end{array}$ & 0 vs & 1.648 & 0.767 & 3.541 \\
\hline $\begin{array}{l}\text { W_1_m4 } \\
\text { vs 1 }\end{array}$ & 1.296 & 0.646 & 2.602 \\
\hline
\end{tabular}

Only the coefficients of CLASS, NUM_EDU and SEX were found to be statistically different from 0 with $p$ values less than the 0.05 significance level (table 5).

The model of best fit is thus:

$$
\text { EX_S }=30.466+5.508 \text { Class }+12.048 \mathrm{Sex}+0.85 \mathrm{Num} \text { edu }
$$

This indicates that, for every unit increase in any one variable, the sex (gender) of a student strongly influences the performance of that student. 
Considering all other variables constant, the boy is expected to perform better than the girl in mathematics examination given that the male was coded as 1 and female as 0 . That is, the model for male (1) and female (0) is represented respectively as;

$$
\begin{aligned}
& E X_{\_} S_{\text {MALE }}=42.514+5.508 \text { Class }+0.85 \mathrm{Num} \_e d u \\
& E X_{\_} S_{\text {FEMALE }}=30.466+5.508 \text { Class }+0.85 \mathrm{Num} \text { _edu }
\end{aligned}
$$

Assuming the other variables are constant, it implies boys perform boys (male) outperform girls (female) by a factor of one and half. The result supports the point that there is gender difference in mathematics performance between the male and female students in mixed senior high schools.

Table 5: Analysis of Variance Estimates for CLASS, NUM_EDU and SEX

\begin{tabular}{|l|l|l|l|l|l|}
\hline Variable & Parameter estimates & Standard Error & Type II SS & F Value & Pr $>$ F \\
\hline Intercept & & & & \\
\hline Class & 30.4658 & 4.52469 & 15440 & 45.34 & $<.0001$ \\
\hline Sex & 5.50786 & 1.73401 & 3436.11558 & 10.09 & 0.0017 \\
\hline Num_edu & 12.04833 & 2.37107 & 8793.71835 & 25.82 & $<.0001$ \\
\hline
\end{tabular}

\section{DISCUSSION OF RESULTS}

Results from the chi-square test indicate that CLASS and GEN_DIF are independent of each other. The way of thinking of the student about mathematics and gender does not change rising from the lower class to the higher class of study. CLASS was also found to be independent of whether the student likes mathematics or not. This could mean that, the student still holds the perception or the belief he/she go to school with from first year to the final year.

It is not surprising however, that GENDER has a strong relationship with GEN_DIF. Both students still hold the belief that there is gender difference. Out of 112 girls who were captured in the sample, 73 $(29.20 \%)$ of the responded that, boys do not perform more than girls in mathematics exams. 39(15.60\%) stated that there is difference in performance in mathematics between the boy and the girl. $118(47.20 \%)$ agreed there is gender difference in mathematics performance while $20(8.00 \%)$ did not agree.

Teachers have the same belief that there is gender difference in mathematics performance between the boy and the girl with the boy expected to perform better than the girl. This is seen from the sample results of the 15 teachers sampled. Only one out of the 15 teachers argued that there is no difference in mathematics performance between the boy and the girl. This alone discourages the girl child from putting up a challenge against the boy in mathematics examination. Most of these teachers had not trained as educators. Though most of them did math-based courses, they are not trained teachers and possibly not exposed to appropriate teaching methodology. Having interest in a subject is a positive indication that that student would develop interest in further math-related courses. $13.60 \%$ of the students who do not like mathematics took the risk to register for math-based arts and math-based science. $52.40 \%$ of those who like mathematics chose to do math-related courses while $24.00 \%$ opted for non-math related courses. The third response variable, school drop-out 0 , had 132 YES responses and 118 NO responses.

The main reason for this research was based on whether there is gender difference between the boy and the girl in mixed senior high schools in the Upper East Region of Ghana. The analysis of the investigation using qualitative factors such as;

- Girls lack self-confidence

- Teachers' questioning methods

- Teachers praise boys and girls differently and

- Teachers' belief of gender difference, were included in the questionnaire. The results showed that the model fitted as a whole was significant $\left(L R X^{2}=39.36, p=0.0001\right)$. 
Further results indicated that there is no significant effect of "teachers praise boys and girls differently (0.4065)" and "teachers' belief of gender difference (0.9215)" whereas "girls lacks self-confidence (0.0001)" and "teachers questioning methods (0.0361)" were significant.

One of the principal objectives of this research was to analyse the reasons why students like/dislike mathematics. Interest plays a part in every life's activity. "What is your reason for studying mathematics?" (LIKE_M) and" Do you have to be clever before studying mathematics?" (W_L_M) in the questionnaire was designed for this purpose. According to the analysis, a first look at the overall model seem to decide that, almost all the predictor variables influence students interest in mathematics. But this is not the case.

The logistic regression analysis above indicates that, students like mathematics for teaching methods (W_L_M1) and personal interest (W_L_M2). This tells us that if more trained teachers, particularly mathematics teachers, are available in the classrooms, the question of gender difference on academic performance in mathematics examination would reduce to its minimum since students are appreciating mathematics for this reason.

Does the performance of the student depend on at least one of the following:

- Age of the student,

- Class of the student,

- Sex of the student,

- Number of people in the student's household or the number of people who are educated in his/her household.

One is tempted to conclude that the variables listed are associated with final mathematics examination performance. The regression output $t$, spells it clear the variables that contribute to the score the student is expected to get in mathematics examination. Thus, the CLASS of the student, the SEX and the number of educated people in the student's household (NUM_EDU) strictly influence the student's ability in mathematics performance in the classroom.

\section{CONCLUSION AND RECOMMENDATIONS}

Results indicate that there is gender difference in the outcome of mathematics examinations in Upper East Mixed Senior high schools. Specifically, this investigation shows that there is gender difference with boys performing better than girls. This was ascertained from both students and teachers from selected schools in the Upper East region. A number of factors were suggested for the difference in performance in mathematics between the boy and the girl.

Now that we know what factors are causing the low performance of girls in mathematics in the mixed senior high schools in relation to boys, how do we minimize or eliminate if possible? Science and technology have become the basic tools for development of modern society. A measure of a nation's development can be ascertained from the quality and quantity of its scientific output and mathematics provide the bedrock on this scientific work. A nation that neither develops a scientifically literate citizenry nor attracts sciences is doomed to remain undeveloped no matter its natural resources. Women for that matter young growing girls are part of the citizenry of this nation and therefore needs to be educated scientifically beginning the first mathematics experience such that development of this nation does not come to a halt in the near future.

It is obvious that in current educational reforms that mathematics is a tool for science and technology and it will continue to take pre-eminence in the society and at all levels of educational strata. For this to take proper effect, teachers and parents alike needs to give equal type of attention to the girl as compared to the boy both in the classroom and outside the classroom.

From the study, students' examination score in mathematics depends largely on the class, sex and the number of educated people in the house. It is reasonable to think that the boy outperforms the girl as the level of class progresses from SHS one through SHS three. And because people have the perception that mathematics is male domain, the boy gets more help in mathematics than the girl even in the house where an educated person may be found. Educated people who pass through the system where girls were considered inferior to boys when it comes to mathematics pass on this perception to the younger generation and this could be the reason why such differences in mathematics performance exist between the sexes.

Students need to be constantly encouraged to keep the good performance as the level of class progresses so that, they do not relax in a course just because one or two influential people are saying such course is for male or female. In looking out for the relationship between suggested factors and the interest of students in mathematics yielded a 
significant result. But only few were actually linearly related to whether a student likes mathematics or not and why. Teaching methods and personal interest strongly influences students' interest in mathematics according to the investigation.

It was also clear that the effect of gender difference on the students are school drop-out and that, girls make poor future choices relative to boys. More students especially girls drop out of school when they realise that they are not going to make because of mathematics. This is evident from fact that students perform well in other subjects and fail to make in mathematics and end up writing private exams each year just to have a pass in mathematics in other to go further in his/her education.

One-way decision making and weak capacity to educate are major impacts of gender difference in both districts. Not until recent times, women are always seen as not part of decision making in the district. This was due to the fact that, the only place a woman could was as a secretary in the office, and so, decisions are made without her.

It is also recommended that GES and NGOs who go into education, and the Universities, should organize refresher courses for teachers in both sectors to update the knowledge in their respective teaching courses. Teachers must be retrained to ensure that boys and girls are treated equally.

Furthermore, graduate teachers who do not study Education as part of their undergraduate programmes before teaching should be given the chance to do education to acquire the necessary teaching methodologies in other to teach students satisfactorily. A post-graduate diploma programme for holders of first degrees must be given due consideration by every University in Ghana.

\section{REFERENCES}

Banaji, M. R., Greenwald, A. G. \& Nosek, B. A. (2002). Math=male, me=female, therefore math=me. Journal of personality and social psychology, 83, 44-59
Campbell, P. B, and Storo, J. N. (1996). Girls are..., Boys are...: Myths, Stereotypes, and Gender Differences. $5 \mathrm{pp}$

Fennema, E. and Sherman, J. (1978). Sex-related differences in mathematics achievement and related factor: A Further Study. Journal for Research in Mathematics Education, 9(3), pp. 189-203

Hazel, C. (1998). A comparison of gender-related attitudes towards mathematics between girls in single-sex and co-educational schools. A Research paper. pp10

Nokoe, K S (2008). The marriage of Mathematics and Biology: life assessment for sustainable development. Inaugural lecture, Ghana Academy of Arts and Sciences, Accra $3^{\text {rd }}$ April 2008, 56pp

Shields, C. (1991). Girls, math, and the Glass Ceiling. Curriculum Review, 30(6), pp. 8-12

Streitmatter, J. (1997). An exploratory Study of risk-taking and attitudes in a girls-only middle school math class. The Elementary School Journal, 98, pp. 15-26

Sadker, M., D. Sadker, and S. Klein (1991). "The Issue of Gender in Elementary and Secondary Education". Review of Educational Research 17: pp. 269-334

Tobias, S. (1978). Overcoming Math Anxiety. Boston: Houghton Mifflin

Teye, J. T. (2006). The Analysis of the causes and impact of poverty using regression classification procedure: Case of the Dangme West District of the Greater Accra Region of Ghana. p. 21, pp. 26

http://www.fordham.edu/mathematics/whatmath.html (accessed November 24, 2007)

http://www.ed.gov/pubs/EarlyMath/whatis.html_(accessed November 24, 2007)

http://www.ats.ucla.edu/stat/stata/dae (accessed March 2024, 2008)

http://www.ats.ucla.edu/stat/sas/notes2/(accessed November 24, 2007).

http://www.ats.ucla.edu/stat/stata/faq/oratio.htm (accessed April 4, 2008) 